\title{
Changes in respiratory variables of grain handlers and civic workers during their initial months of employment
}

\author{
I BRODER, M A HUTCHEON, S MINTZ, G DAVIES, A LEZNOFF, P THOMAS, \\ AND P COREY \\ From the Gage Research Institute, Toronto, and Department of Medicine, University of Toronto, Toronto, \\ Ontario, Canada
}

ABSTRACT The health effects of employment as a grain handler were studied by examining workers on two occasions, firstly, immediately before or soon after they were hired and again about two and a half months after they were employed. Over this time there was a substantial increase in the prevalence of cough, sputum, and eye irritation, accompanied by small pulmonary function changes suggestive of a restrictive ventilatory defect. No comparable changes in symptoms were observed over a similar number of months in grain handlers employed for an average of nine years or in control workers consisting of newly hired or long term civic outside labourers. The long term grain handlers, however, developed a similar change in their pulmonary function. These findings indicate the occurrence of a change in the health of grain elevator workers after a relatively brief duration of employment.

With other groups, we have been studying the health of grain handlers, using an epidemiological approach in which these workers are compared with control subjects employed in a different occupation..$^{1-4}$ This type of study, whether cross sectional or longitudinal, can be biased as a result of selection factors which may influence both whether people seek employment in either occupation or whether, once hired, they remain employed. We have undertaken the present study, in which grain handlers and control subjects were first examined close to the start of their employment and were re-examined after they had been working for about two and a half months, to examine short term health effects free from the bias of affected workers who may tend to quit over longer periods.

\section{Methods}

SUBJECTS

Two examinations were performed two to four months apart on each of two sets of grain elevator workers and civic outside labourers. The first set consisted of new employees of either the Saskatch-

Received 18 October 1982

Accepted 6 December 1982 ewan Wheat Pool in Thunder Bay or the public works department of the City of Thunder Bay. Each worker was initially examined within an average of one week of their having started to work in May or June of 1978 and 1979 in the case of the grain handlers and only in 1979 for the civic workers. The second examination was performed about two and a half months after they were hired. Our access to a given worker was mainly at the discretion of the supervisor. A process of informed consent that had been approved by the Office of Research Administration of the University of Toronto was used.

About half the grain handlers and civic workers who participated were newly hired during the period of our study. Grain handlers who had been employed in this occupation previously were excluded, since they might have represented a selected subgroup. The first examination was completed in 47 grain handlers and 21 civic workers, and of these, 39 and 18 respectively underwent the second examination. Those in whom the second examination was not completed had either quit ( 3 grain, 1 civic), been fired ( 2 grain), or repeatedly did not appear for their appointments ( 3 grain, 2 civic). None of those who quit had done so for health reasons. Full pulmonary function data were available for both examinations in 27 grain handlers and 14 civic workers, to whom 
Table 1 Characteristics of newly hired grain handlers and civic outside labourers, each examined on two occasions within the same year

\begin{tabular}{|c|c|c|c|c|c|c|}
\hline & \multicolumn{3}{|c|}{ Grain handlers } & \multicolumn{3}{|c|}{ Civic workers } \\
\hline & May-June & August & $p$ value* & May-June & August & $p$ value \\
\hline No of subjects & 27 & 27 & & 14 & 14 & \\
\hline Age & $24 \pm 7$ & & & $21 \pm 2$ & & \\
\hline \multirow{2}{*}{\multicolumn{7}{|c|}{ Smokers: }} \\
\hline & & & & & & \\
\hline Non-smokers & $26 \%$ & $26 \%$ & & $86 \%$ & $86 \%$ & \\
\hline Ex-smokers & $15 \%$ & $11 \%$ & & & & \\
\hline Current smokers & $59 \%$ & $63 \%$ & & $14 \%$ & $14 \%$ & \\
\hline Cough $\geqslant$ few days/week & i $5 \%$ & $52 \%$ & 0.002 & $14 \%$ & $14 \%$ & \\
\hline Sputum $\geqslant$ few days/week & $11 \%$ & $33 \%$ & 0.03 & $7 \%$ & $7 \%$ & \\
\hline Rhinitis $\geqslant$ few days/week & $7 \%$ & $19 \%$ & & $43 \%$ & $36 \%$ & \\
\hline Eye irritation & $0 \%$ & $30 \%$ & 0.008 & $7 \%$ & $14 \%$ & \\
\hline Rash & $4 \%$ & $15 \%$ & & $14 \%$ & $7 \%$ & \\
\hline Skin tests $\geqslant 1$ positive & $7 \%$ & & & $36 \%$ & & \\
\hline FVC $\ddagger$ & $106 \pm 14$ & $104 \pm 12$ & 0.02 & $101 \pm 8$ & $101 \pm 5$ & \\
\hline RV & $102 \pm 35$ & $96 \pm 34$ & & $101 \pm 25$ & $117 \pm 28$ & 0.05 \\
\hline TLC & $99 \pm 12$ & $97 \pm 11$ & 0.06 & $96 \pm 6$ & $98 \pm 8$ & \\
\hline FEV $_{1}$ & $104 \pm 14$ & $107 \pm 12$ & 0.04 & $104 \pm 10$ & $101 \pm 10$ & \\
\hline$V_{\max } 50 \% \mathrm{VC}$ & $111 \pm 30$ & $107 \pm 28$ & & $109 \pm 21$ & $104 \pm 23$ & \\
\hline$V \max _{25 \% \mathrm{VC}}$ & $107 \pm 42$ & $102 \pm 39$ & & $105 \pm 29$ & $102 \pm 32$ & \\
\hline
\end{tabular}

*Within group comparisons were performed using the McNemer or paired $t$ test. A blank indicates a p value greater than $0 \cdot 05$.

$\dagger$ Mean \pm standard deviation.

$\ddagger$ Pulmonary function results are expressed as percentage of age-height predicted values.

the following analysis was restricted. Those 12 grain handlers and four civic workers who were excluded on this basis were missing one or more values in the six paired tests of pulmonary function used in this analysis. The characteristics of the final groups (table 1) did not differ from the 20 grain and seven civic workers who were deleted on the foregoing grounds.

The second set of subjects consisted of 31 grain handlers and 13 civic outside workers who had been employed in their respective occupations for an average of nine years. These workers were a subset from two larger groups consisting of 56 grain handlers and 26 civic workers who were being examined at quarterly intervals over a 12 month period beginning in November 1979. Both full groups were selected randomly from among those we had examined in previous surveys on the basis of being comparable in age and smoking experience. The subsets included in this report were drawn entirely on the basis of having undergone examinations in both the May-June interval and in September 1980. No examinations in this survey could be carried out in August 1980, which accounts for the longer interval between the two examinations of the subjects in the second set ( 123 to 135 days) relative to that in the newly hired workers ( 68 to 82 days).

The paired examinations of each subject belonging to both sets were always done in the same half of the shift and on the same day of the week, plus or minus one day. The mean day of the week in which the first and second examination was performed in each set of grain and civic workers did not differ by more than one day between visits within a given group or for a given visit between groups.

\section{SURVEY PROCEDURES}

Both examinations of each subject included the administration of a health questionnaire and pulmonary function tests. Skin tests were also performed on the newly hired workers.

The questionnaires were styled in the same manner as those we have used previously in this population. ${ }^{15}$ Information was collected on the presence and frequency of cough, sputum, wheeze, shortness of breath, rhinitis, respiratory illness, conjunctival irritation, and rash. (Copies of the questionnaire are available on request.) The orientation of the same questions at the second assessment was towards the interval since the previous visit. The questionnaire was administered to the newly hired workers by a physician and to the long term employees by a lay interviewer who was trained by the senior author and observed to apply the questions in the same manner as the physicians.

Skin tests were performed with a Von Pirquet scarifier using the following antigens prepared in $50 \%$ glycerine (Hollister-Stier, Toronto): barley dust, flaxseed, oat dust, rapeseed, rye dust, wheat dust, Alternaria spp, Asperigillus fumigatus, Aspergillus mix, Cladosporium, Fusarium, Mucor racemosus, Pencillium mix, Rhizopus nigricans, yeast, aspen pollen, paper birch pollen, house dust, and grass pollen. The pollens were used in a strength of $1: 20$ (weight/volume) and the others, 1:10. A negative control and a positive control, consisting of 
histamine $1 \mathrm{mg}$ per $\mathrm{ml}$, were also used. A positive reaction to a test antigen consisted of a weal and flare larger than that produced by the negative control.

The pulmonary function tests included a maximal expiratory flow volume curve, using a wedge spirometer equipped with a one second time marker. Replicate curves for a given subject were superimposed at total lung capacity and the manoeuvre was repeated until two tracings were obtained that corresponded within $5 \%$ both for forced vital capacity (FVC) and for flow over the lowest $70 \%$ of vital capacity. The best curve based on acceptable effort, with the largest FVC and flow rate, was used to measure the forced expiratory volume in one second $\left(\mathrm{FEV}_{1}\right)$, the FVC, and the maximal expiratory flows at $50 \%$ and at $25 \%$ of the FVC ( $\dot{\mathrm{V}} \max { }_{50 \% \mathrm{VC}}$ and $\dot{\mathrm{V}} \max _{25} \% \mathrm{vC}$

Lung volume measurements were made by helium dilution in $1978^{\circ}$ and by using a constant volume plethysmograph in 1979 and $1980 .^{7}$ The lung volume data were used only to compare the results obtained at the first and second examinations within the same individual, using paired $t$ tests. Thus we were able to combine the lung volume measurements for the newly hired grain handlers examined in 1978 and 1979 , since the two results for each subject were always obtained by the same method. All pulmonary function data were expressed in BTPS as a percentage of the age-height predicted values, using the formula of Goldman and Becklake for the FVC, TLC, and RV, ${ }^{8}$ Morris and associates for the $\mathrm{FEV}_{1},{ }^{9}$, and Lapp and Hyatt for the $\dot{\mathrm{V}} \max _{50 \% \mathrm{VC}}$ and $\dot{\mathrm{max}}_{25 \% \mathrm{VC}}{ }^{10}$

Statistical analysis was performed using analysis of variance and paired and unpaired $t$ tests for continuous data and the McNemar and chi square tests for nominal data. Univariate relationships were examined using logistic and linear regression analysis. Datatext and Statistical Analysis System packages were employed, using the facilities of the University of Toronto Computer Centre.

\section{Results}

\section{NEWLY HIRED WORKERS}

The results obtained at the initial examination indicated that the newly hired grain handlers were, on average, three years older than the civic workers, but the difference was not statistically significant (table 1). The average duration of employment was about one week in both groups. The frequency of current smokers was significantly higher among the grain than the civic workers $(p=0 \cdot 03)$. Cough and sputum production were equally prevalent in both groups, whereas rhinitis was significantly lower among the grain handlers $(\mathrm{p}=0 \cdot 03)$. Positive skin reactions were found less commonly among the grain elevator workers, but this difference had a probability of greater than 0.05 . The pulmonary function results obtained from the flow volume curves showed no significant differences between the two groups.

The second examination was conducted after both groups of subjects had been employed an average of 10 to 12 weeks (table 1). During this interval the frequency of cough, sputum, and eye irritation increased significantly among the grain handlers and there was a small increase in the frequency of rhinitis and rash which was not significant. The civic workers showed no appreciable changes. The grain handlers exhibited a small but significant decrease in their FVC from the first to the second assessment (table 1). There was an associated decrease in their RV, TLC, and flow rates, but these changes were not statistically significant; there was a small but significant increase in the $\mathrm{FEV}_{1}$, however. By contrast, the civic workers showed a significant increase in their residual volume with no appreciable change in their FVC or TLC and a small decrease in their $\mathrm{FEV}_{1}$ and flow rates. On comparing the changes in pulmonary function results obtained between the two visits of the grain handlers and civic workers, a significant difference was found for the FEV, $(p=0.02)$, the RV $(p=0.02)$, and the TLC $(\mathrm{p}=0.02)$.

The alterations in symptoms and pulmonary function between the initial and second examination among the grain handlers were similar when the data were collected in 1978 or 1979 and in smokers or non-smokers. Also, we could show no relationship between the interval separating the first and second examination of each subject and the development of cough or sputum or the change in pulmonary function.

\section{LONG TERM WORKERS}

An examination similar to that carried out on the newly hired workers was conducted on two occasions during the same period of 1980 in 31 grain handlers and 13 civic outside workers who had been employed for an average of nine years. The long term grain handlers and civic workers showed no significant differences at the initial examination, although the former group had a lower frequency of members who smoked or had sputum and a higher proportion reporting nasal symptoms or conjunctival irritation and higher flow rates (table 2).

Varying characteristics of both groups differed from those obtained at the initial visit of the respective newly employed workers, in addition to their 
Table 2 Characteristics of long term grain handlers and civic outside labourers, each examined on two occasions within the same year

\begin{tabular}{|c|c|c|c|c|c|c|}
\hline & \multicolumn{3}{|c|}{ Grain handlers } & \multicolumn{3}{|c|}{ Civic workers } \\
\hline & May-June & September & $p$ value ${ }^{*}$ & May-June & September & $p$ value \\
\hline No of subjects & 31 & 31 & & 13 & 13 & \\
\hline Age (years) & $32 \pm 9+$ & & & $34 \pm 9 \dagger$ & & \\
\hline Years since hired & $9 \pm 3$ & & & $9 \pm 7$ & & \\
\hline \multicolumn{7}{|l|}{ Smokers: } \\
\hline Non-smokers & $32 \%$ & $29 \%$ & & $15 \%$ & $8 \%$ & \\
\hline Ex-smokers & $19 \%$ & $16 \%$ & & $8 \%$ & 0 & \\
\hline Current smokers & $49 \%$ & $55 \%$ & & $77 \%$ & $92 \%$ & \\
\hline Cough $\geqslant$ few days week & $53 \%$ & $43 \%$ & & $54 \%$ & $38 \%$ & \\
\hline Sputum $\geqslant$ few days/week & $40 \%$ & $37 \%$ & & $54 \%$ & $38 \%$ & \\
\hline Rhinitis $\geqslant$ few days/week & $40 \%$ & $37 \%$ & & $23 \%$ & $23 \%$ & \\
\hline Eye irritation & $23 \%$ & $27 \%$ & & 0 & $8 \%$ & \\
\hline Rash & $17 \%$ & $7 \%$ & & $8 \%$ & 0 & \\
\hline FVC $\ddagger$ & $106 \pm 12$ & $103 \pm 12$ & $0 \cdot 001$ & $108 \pm 12$ & $108 \pm 12$ & \\
\hline RV & $93 \pm 26$ & $95 \pm 26$ & & $95 \pm 31$ & $95 \pm 32$ & \\
\hline TLC & $106 \pm 13$ & $105 \pm 13$ & & $108 \pm 11$ & $109 \pm 13$ & \\
\hline $\mathrm{FEV}_{1}$ & $113 \pm 15$ & $109 \pm 14$ & 0.001 & $110 \pm 13$ & $108 \pm 13$ & \\
\hline$V \max _{25} \% \mathrm{VC}$ & $95 \pm 34$ & $89 \pm 38$ & 0.01 & $65 \pm 30$ & $61 \pm 28$ & \\
\hline
\end{tabular}

*Within group comparisons were performed using the $\mathrm{McNemer}$ or paired $t$ test. A blank indicates a $\mathrm{p}$ value greater than $0 \cdot 05$. † Mean \pm standard deviation.

$\ddagger$ Pulmonary function results are expressed as percentage of age-height predicted values.

being older (tables 1 and 2). There were more current smokers among the long term civic workers than those newly hired $(77 \% v 14 \%, \mathrm{p}=0.001)$. Respiratory and other symptoms were reported more frequently in the long term than in the newly hired grain handlers, and approximated those observed at the second examination of the latter group (cough respectively $53 \% \vee 15 \%, \mathrm{p}=0.01$; sputum $40 \% \vee 11 \%, \mathrm{p}=0.05$; rhinitis $40 \% \vee 7 \%$, $\mathrm{p}=0.01$, and eye irritation $23 \% v 0 \%, \mathrm{p}=0.05)$. The prevalence of symptoms among the civic workers differed only in that the long term group showed a higher frequency of cough and sputum (cough respectively $54 \% \vee 14 \%, \mathrm{p}=0.1$ and sputum $54 \%$ $v 7 \%, \mathrm{p}=0.05)$. The pulmonary function results obtained from the flow volume curves did not differ significantly between the respective long and short term groups, with the exception of a lower $\dot{V} \max _{25} ; \mathrm{vc}$ in the long term than in the newly employed civic workers (respectively $65 \%$ of predicted $v$ $105 \%, \mathrm{p}=0.01)$. We presume that the difference in cough, sputum, and $\overline{\mathrm{V}} \max _{25 \% \mathrm{VC}}$ among the long term and new civic workers was related to the disparity in their smoking habits.

The second examination was conducted an average of 123 days after the first in the long term grain handlers and 135 days in the civic group. Neither group showed a significant change in symptoms or smoking habit (table 2). The long term grain workers showed a small but statistically significant decrease in their FVC, FEV , and flow rates, which was similar in both smokers and non-smokers. There was no significant change in the pulmonary function of the civic workers although their FEV, arid flow rates also decreased slightly. The change in pulmonary function from the first to the second examination was significantly different between the grain and civic workers only for the FVC $(p=0.02)$.

The statistical analysis of the pulmonary function changes obtained within both the newly hired and long term workers yielded similar results when analysed by paired $t$ tests (tables 1 and 2 ) or by the Wilcoxon signed rank test.

\section{Discussion}

The frequency of smoking among the newly hired civic workers was strikingly lower than in the newly hired grain handlers or the long term grain handlers and civic workers (tables 1 and 2). This was probably because students comprised $79 \%$ of the newly hired civic workers, $22 \%$ of the newly hired grain handlers, and none of the long term workers, while only $12 \%$ of all the students were current smokers.

The difference in the proportion of students between the newly hired grain and civic workers may also have accounted for the higher frequency of rhinitis in the latter group, since the prevalence of this complaint among students in the grain handler group was $33 \%$, which approximated that in the civic workers (table 1 ). The same was true for the disparity in positive skin test results, all of which occurred in the grain handlers who were students. Nevertheless, our present finding of a decreased frequency of positive skin reactions in grain handlers compared with control workers was consistent with previous results obtained both by Gerrard and his coworkers and by our own group.' "The maldis- 
tribution of the students did not account for the change in the symptoms or pulmonary function results of the grain handlers over the initial two and a half months of employment, since the students and non-students behaved alike in this respect.

The prevalence of cough, sputum, and eye irritation increased substantially in the newly hired grain handlers during their initial three months of employment (table 1). These symptoms did not change over the same period in the civic group, suggesting that cough, sputum, and eye irritation may be more selective indicators of the health effects of employment as a grain handler than symptoms such as rhinitis and rash. This finding also indicates the relative rapidity with which these effects became established.

Cough and sputum were equally frequent not only in the grain handlers employed for three months or nine years but also in the long term civic workers. This suggests that the frequency of cough and sputum lacks selectivity after long term employment as a grain handler, perhaps because the effects of smoking begin to dominate with the passage of time. The results of our previous large scale cross sectional study would be consistent with this interpretation, since it indicated an equal frequency of these symptoms among grain handlers and civic workers who were current or ex-smokers and had an average duration of employment in excess of 10 years'; only in non-smokers was there a small excess of cough and sputum among the grain handlers. Nevertheless, other factors also may contribute to the equality of cough and sputum in long term grain and civic workers, as is suggested by our observations made during a second large scale cross sectional study of the same workers performed three years later. Here we found a significant excess of cough and sputum among the grain handlers who had quit their job luring the interval by comparison with those who remained employed (unpublished observations). This was not seen among the civic workers who gave up their positions. These observations suggest that the grain handlers who develop adverse effects tend to leave the job.

The possibility could be raised that the inequality of cough and sputum in grain and civic workers employed for two and a half months and the equality of these symptoms in grain and civic workers employed for nine years may represent a process of acclimatisation in the grain handlers. We had, however, shown previously a decline in cough during a two month period of layoff and a worsening of cough and sputum after rehire in grain handlers who had been employed for an average of four years. ${ }^{5}$ These changes were similar to those we observed during the initial two and a half months of employment as a grain handler in the present study (table 1). Thus our past results suggest that acclimatisation to grain dust may not occur, at least within four years. Moreover, the earlier results indicate that the cough and sputum associated with employment as a grain handler are reversible within the same duration of employment.

The changes in pulmonary function that occurred over the initial two and a half months of employment as a grain handler were small but were consistent with the occurrence of mild ventilatory restriction (table 1), whereas those of the civic workers were suggestive of slight airway obstruction. Similar changes were respectively observed in long term grain handlers and civic workers (table 2). We reported previously that grain handlers and civic workers who were tested at the beginning and end of a week of work ${ }^{12}$ showed changes comparable with those observed in the present study. Also, our past

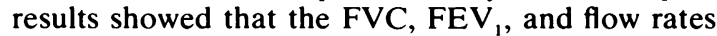
of grain handlers increased during a period of layoff and then decreased after rehire. ${ }^{5}$ These findings indicate that, like cough and sputum, the changes in pulmonary function observed in the newly hired grain handlers are likely to be at least partially reversible.

The level of activity in the grain elevators of Thunder Bay is lowest from January to March and is then relatively high throughout the remainder of the year. ${ }^{5}$ Thus the months during which our present data were collected (in 1978, 1979, and 1980) corresponded with the initial months of increased activity during each year. We presume that the change in pulmonary function of the long term grain handlers was related to this cyclical increase in industrial activity. We have suggested previously that the slight obstructive change observed in civic outside labourers was related to their exposure to dust arising either from their handling of refuse or their involvement in road repair and construction. ${ }^{12}$

Our present experience using newly hired workers to assess the health effects of employment as a grain handler has shown at least two advantages over the more conventional large scale cross sectional study. Firstly, we have been able directly to observe the latency of work related health effects. Secondly, we have avoided the bias introduced when workers who develop health effects tend to quit, leading to an underestimate of morbidity in cross sectional studies. This approach has potential value mainly in occupations associated with health effects of relatively short latency.

This work was supported by a grant from Health and Welfare Canada. We are grateful to the Saskatchewan Wheat Pool, the Canadian Lakehead Grain 
Elevator Workers, the City of Thunder Bay, and Local 87 of the Canadian Union of Public Employees for their cooperation in this study. We thank Nicola Wachmann, Jon Kuzyk, Brian Batten, Peter Olver, and Bruce Urch for their technical help, Lee Angus for coordination of the studies, and Cheri Aitken and Marilyn Okada for the data management and statistical programming.

\section{References}

' Broder I, Mintz S, Hutcheon M, et al. Comparison of respiratory variables in grain elevator workers and civic outside workers of Thunder Bay, Canada. Am Rev Respir Dis 1979;119:193203.

2 Dosman JA, Cotton DJ, Graham BL, Li KYR, Froh F, Barnett GD. Chronic bronchitis and decreased forced expiratory flow rates in lifetime nonsmoking grain workers. Am Rev Respir Dis 1980;121:11-6.

${ }^{3}$ Chan-Yeung, $M$, Schulzer $\mathbf{M}$, MacLean L, Dorken E, Grzybowski S. Epidemiological health survey of grain elevator workers in British Columbia. Am Rev Respir Dis 1980;121:329-38.

${ }^{4}$ Becklake MR, Jodoin G, Lefort L, Rose B, Mandl M, Fraser RG. A respiratory health study of grainhandlers in St Lawrence river ports. In: Dosman JA, Cotton DJ, eds. Occupa- tional pulmonary disease: focus on grain dust and health. New York: Academic Press, 1980:239-55.

${ }^{5}$ Broder I, Mintz S, Hutcheon MA, Corey PN, Kuzyk J. Effect of layoff and rehire on respiratory variables of grain elevator workers. Am Rev Respir Dis 1980;122:601-8.

- Macklem PT. Procedures for standardized measurements of lung mechanics. Bethesda, Maryland: National Heart and Lung Institute, Division of Lung Disease, 1974.

' DuBois AB, Botelho SY, Bedell GN, Marshall R, Comroe JH Jr. A rapid plethysmographic method for measuring thoracic gas volume: a comparison with a nitrogen washout method for measuring functional residual capacity in normal subjects. $J$ Clin Invest 1956;35:322-6.

" Goldman HI, Becklake MR. Respiratory function tests. Normal values at median altitudes and the prediction of normal results. Am Rev Tuberc 1959;79:457-67.

- Morris JF, Temple WP, Kóski A. Normal values for the ratio of one-second forced expiratory volume to forced vital capacity. Am Rev Respir Dis 1973;108:1000-3.

${ }^{10}$ Lapp NL, Hyatt RE. Some factors affecting the relationship of maximal expiratory flow to lung volume in health and disease. Dis Chest 1967;51:475-81.

" Gerrard JW, Mink J, Cheung S-SC, Tan LK-T, Dosman JA. Nonsmoking grain handlers in Saskatchewan: airways reactivity and allergic status. JOM 1979;21:342-6.

${ }^{12}$ Corey P, Hutcheon M, Broder I, Mintz S. Grain elevator workers show work-related pulmonary function changes and doseeffect relationships with dust exposure. $\mathrm{Br} J$ Ind Med 1982;39:330-7. 